June - 2016

\title{
Effects of Group Awareness and Self-Regulation Level on Online Learning Behaviors
}

Jian-Wei Lin ${ }^{1}$, Yu-Chin Szu², and Ching-Neng Lai ${ }^{3}$

${ }^{1}$ Chien Hsin University, Taiwan, ${ }^{2}$ St. John's University, Taiwan, ${ }^{3 H}$ sing Wu University, Taiwan.

\begin{abstract}
Group awareness can affect student online learning while self-regulation also can substantially influence student online learning. Although some studies identify that these two variables may partially determine learning behavior, few empirical studies or thorough analyses elucidate the simultaneous impact of these two variables (group awareness and self-regulation) on online learning behavior. This paper compared one online collaboration environments with GA support with one without group awareness (NA) support and further investigated how these two variables, different system types (i.e., GA and NA) and different self-regulation levels (i.e., high and low), influence learning task (i.e., assessment) participation, and peer interaction (i.e., asking for help and willing to help) using two-way analysis of variance (ANOVA). Analytical results first showed that both variables have significant interaction on assessment participation and requesting rate. GA can particularly stimulate students with high-level self-regulation to engage more learning task (assessment) participation and ask for help more, compared with students with low-level self-regulation. Second, both variables have no significant interaction on willingness to help. The GA class can enhance a student's willingness to help regardless of his/her self-regulation level.
\end{abstract}

Keywords: Online collaboration learning, group awareness, self-regulation 


\section{Introduction}

The first subsection discusses the GA-related studies and how these GA online systems influenced learning behavior. The second subsection discusses the influences of self-regulation in an online learning environment. The final subsection elicits our research issues.

\section{The Influence of Group Awareness (GA) in an Computer-Supported Collaborative Learning (CSCL) Environment}

An array of studies on CSCL has demonstrated that effective learning from collaboration is rarely achieved solely by bringing students together (Kreijns, Kirschner, \& Jochems, 2003; Kwon, Hong, \& Laffey, 2013). Visually representing member activity back to a group encourages participation and contribution to group work (Janssen, Erkens, Kanselaar, \& Jaspers, 2007; Kimmerle \& Cress, 2008; Kwon et al., 2013). Group awareness (GA) refers to being informed about members' learning interaction or the knowledge context (Bodemer \& Dehler, 2011) and can afford students more opportunities to engage in self-observation and self-reflection (Holocher-Ertl, Fabian, Siadaty, Jovanović, Pata, \& Gasevic, 2011), thus affecting student learning behavior and thinking in a positive way without using direct force or orders (Olasehinde \& Olatoye, 2014).

A GA tool unveils the information of learning interaction or knowledge context of peers (or group members) to implicitly guide learners' behavior, communication, and reflection (Dehler, Bodemer, Buder, \& Hesse, 2011; Engelmann, Tergan, \& Hesse, 2010; Janssen et al., 2007; Janssen, Erkens, \& Kirschner, 2011; Kimmerle \& Cress, 2008; Sangin, Molinari, Nüssli, \& Dillenbourg, 2011). For example, Janssen et al. (2007) investigated the effects of visualization of participation during online collaboration for a historical inquiry task. The GA tool continuously gathers the number of messages sent by group members and their average length and visualizes it in a way that allows group members to easily compare their own participation to the participation of other group members. Kimmerle and Cress (2008) investigated the effects of visualization of the number of contributions a group member given and the average number of contributions of every group in an online discussion forum during online collaboration. Sangin et al. (2011) investigated a GA tool that provides a member with his/her learning partner's level of prior knowledge, which is intended to improve the learners' model of their learning partner's knowledge. The result showed that the tool can enhance communication quality.

However, most GA-related studies did not consider individual learning characteristics (or differences), which might partially cause some discrepancies among the findings of these GA-related studies. For example, some studies reported more equal participation of all group members in a GA environment (Fjermestad, 2004; Janssen et al., 2007), whereas some reported dominance of some group members (Savicki, Kelley, \& Ammon, 2002). Meanwhile, Sangin et al. (2011) stated that GA can enhance the 
quality of knowledge transfer between all members, while Engelmann et al. (2010) showed the opposite opinion. Some members might consider peers' advices, opinions, or requests of others, help others to accomplish their personal goals while some might choose to ignore others' actions (Shi, Frederiksen, \& Muis, 2013). Group awareness still has a number of open research questions and boundary conditions to be explored (Buder, 2011). One major issue for GA that needs more insight is to clarify how GA influence individual with different characteristics in an online collaborative learning environment.

\section{The Influence of Self-Regulation in an Online Learning Environment}

A highly self-regulated learner can play an active role in learning, setting task-oriented and proper goals, taking responsibility for their own learning, monitoring their own learning, and maintaining their own learning motivation (Schunk, 1994; Zimmerman, 1989). Self-regulation can substantially influence individual learning behavior and effectiveness in an online learning environment (Barnard, Lan, To, Paton, \& Lai, 2009). Thus, several works have investigated how different online learning environments (with support of hypermedia learning content or peer collaboration) affect individual with different self-regulation levels on learning behavior and effectiveness (Lin, Huang, \& Chuang, 2015; McManus, 2000; Wang, 2011). For example, McManus (2000) investigated the impact of a hypermedia learning environment on individual with different self-regulation levels. They found that highly self-regulating learners learn poorly in mostly linear web-based where they have few choices. Meanwhile, low self-regulating learners learn poorly in highly nonlinear web-based hypermedia learning environments where they are given too many choices. Wang (2011) also investigated how an e-learning environment with peer collaboration support influences individual with different self-regulation levels.

\section{Research Issues}

Despite the ability of group awareness and self-regulation to separately influence student learning as described previously, exactly how these two variables (group awareness and self-regulation) impact learning behavior has seldom been addressed.

From the prospective of social cognitive theory, self-regulation cannot be discussed without social contexts (Yowell \& Smylie, 1999). Self-regulation is based not only on individual or intra-psychological processes but also on social or inter-personal processes (Dembo \& Eaton, 2000). Accordingly, self-regulation and group awareness (i.e., unveiling social context) should jointly or interactively influence on learning behavior. Moreover, Barnard et al. (2008) claimed that learner perceptions of peer communication and collaboration (i.e., GA) and individual self-regulation level may partially determine learning behavior and achievement in an online collaborative environment. Shea \& Bidjerano (2012) also stated that GA information may affect students with different 
self-regulation level in adjusting their learning behaviors to achieve the desired outcomes. Shi, Frederiksen, \& Muis (2013) stated that the relationship between individual self-regulated level and GA on collaboration activity is an issue that is still inadequately understood.

Restated, exactly how GA influences the students with different self-regulation levels on learning behavior in an online collaborative learning environment remains contentious. Restated, no empirical study and thorough analysis are available on this topic. This paper compared one online collaborative learning environments with GA support with one without group awareness (NA) support and further investigated how both variables, different systems (i.e., GA and NA) and different self-regulation levels (i.e., high and low), influence learning task (i.e., assessment) participation and peer interaction (i.e., asking for help and willing to help) using two-way ANOVA. Whether both the variables interact with each other for assessment participation and peer interaction were also verified.

\section{Method}

\section{Participants}

This research adopted a quasi-experimental design method. The study was administered to two, third-year classes of a Taiwan university: the first class (the control class) consisted of 53 students using the system without GA support (NA) system; the second class (the experiment class) consisted of 46 students using the system with group awareness support (GA).

\section{Questionnaire to Measure Individual Self-Regulation Levels}

The questionnaire was revised from Lin et al. (2015) who posited that learners scoring high on the questionnaire had a high level of self-regulation during the process of learning. The questionnaire includes 20 questions based on a seven-point Likert scale which ranges from 7 (strongly agree) to 1 (strongly disagree). Five sub-scales are: "self-monitoring" (7 items); "deep strategy use" (4 items); "shallow processing" (4 items); "persistence" ( 2 items); and "environmental structuring" (3 items). The Cronbach's alpha for the questionnaire is 0.81 , and the Cronbach's alpha for each sub-scale is as follows: self-monitoring (0.84); deep strategy use (o.80); shallow processing (0.92); persistence (o.65); and environmental structuring (0.79).

\section{Research Procedure}

Before the experiment, both classes were trained and practiced on how to use their designated systems for one week. During the experiment, both classes were taught by the same teacher and adhered to the same experiment procedure, as shown in Figure 1. At the beginning, both control (NA) class and experiment (GA) classes received the pretest of measuring the self-regulation questionnaire. Within each class, a student with an above average questionnaire score in that class was marked as the student with high-level self-regulation, otherwise, marked as the student with low-level self-regulation. 
Then, both class students were randomly assigned to a group by the teacher according their self-regulation levels (the top block "Pretest and grouping" in Figure 1). More specifically, half of the members of a group in the class were the students with high-level self-regulation while the other half were students with a low-level of self-regulation. Group composition was heterogeneous with respect to self-regulation levels. The participating students collaborated in groups of five or six, as considered by Janssen et al. (2007). In fact, the NA class had nine groups of five or six members while the GA class had eight groups of five or six members.

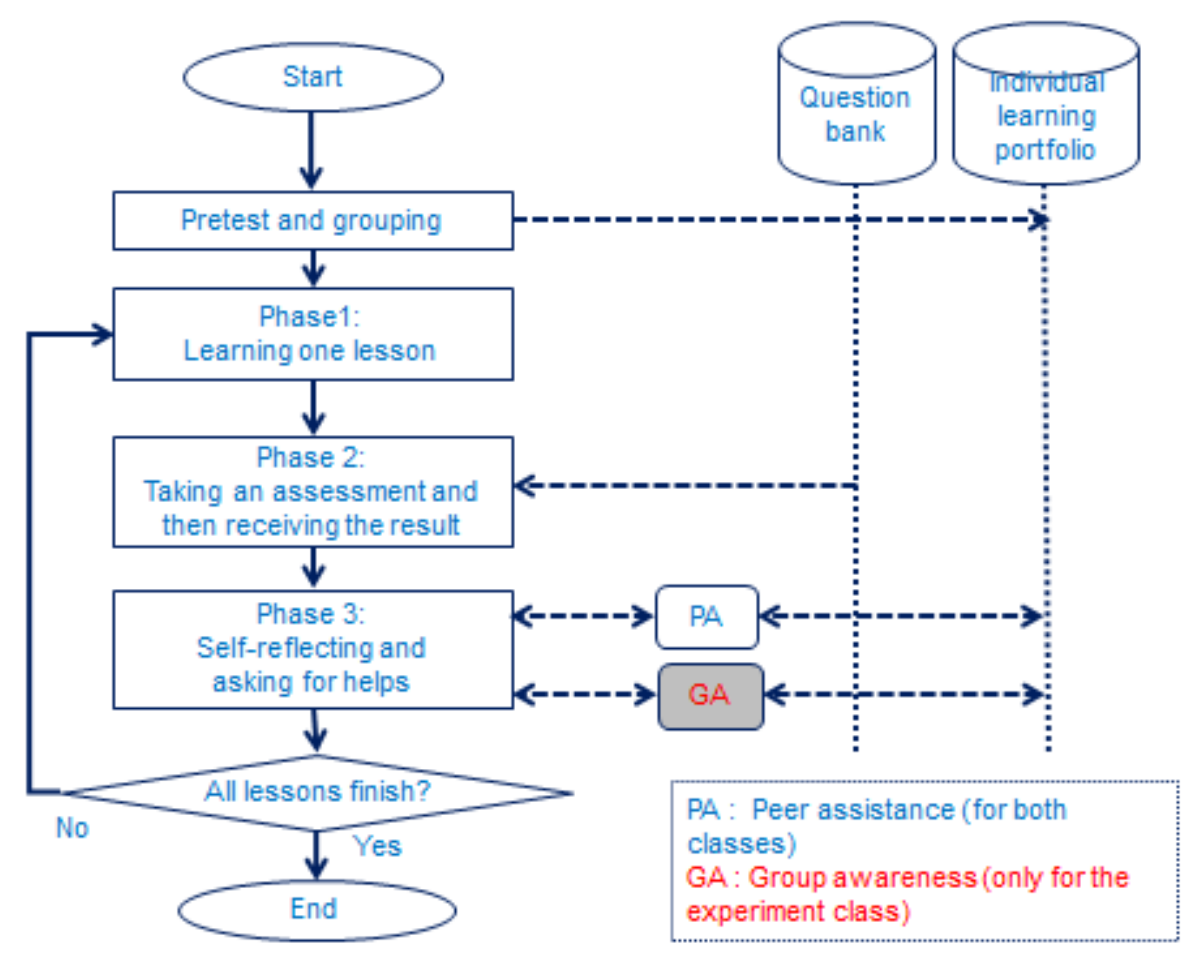

Figure 1. The experiment procedure.

The experimental subject called "Electronic Commerce," involving six lessons, including "Infrastructure and technology," "Strategy development of e-commerce," "Applications of e-commerce," "E-commerce transaction and secure mechanism," "Social network and social ethics," and "E-business." We set a one-week period for each lesson as an indication of learning one lesson, as considered by Lin and Lai (2013). In fact, a new lesson commenced every Wednesday and Friday for both classes respectively and the one-week lesson period lasted until Tuesday and Thursday one week later, respectively. During phase 1 (i.e., at the beginning of one week), both classes received the face-to-face teaching for one lesson. Upon completion of the face-to face teaching for one lesson, both classes entered into phase 2; that is, both classes could freely take the corresponding online assessment once at any time within that week. Upon completion of the assessment, both classes entered phase 3 ; that is, both classes received the assessment results and could self-reflect whether the outcomes were their expectations. The procedure of phase 1 to 3 was repeated until all six lessons 
(i.e., cycles) have completed. Both classes repeatedly experienced the above procedure (i.e., cycles) six times for six weeks. Each assessment consists of multiple-choice questions, whose content primarily originates from face-to-face instructions and teaching materials. The numbers of questions for the six assessments were $20,26,20,22,22$, and 20 . The treatment period should have been enough to develop certain tendencies in students' learning behaviors because students gained more familiarity with their designated environment over an extended period of time (Aleven \& Koedinger, 2001).

In order to analyze peer interaction patterns, this work adopted ask-for-help mechanism; that is, in phase 3 , both classes only received the outcome including question re-stated and their answers whether correct or not after finishing an assessment (i.e., no correct answers were provided for both classes). This mechanism was to lure both-classes students to ask for help during phase 3 (the block "PA" in Figure 1). More specifically, for each incorrect question, both-class student were able to click the corresponding button called "Help request" in Figure 2(a). When clicking the button, a student will get a candidate list which shows all members within the same group who correctly answered the question of the assessment, as shown in Figure 2(b). At this time, a student can select only one candidate and send help messages to the helper. The student receives the help response including the correct answer and its explanation when the helper has responded, as shown in Figure 2(c). Under such system design, a student would ask for help for one candidate for one answered-incorrectly question. However, if the student wants to ask for help for several candidates for the same question, he/she has to repeat the above step for several times (i.e., click the "Help request" button again and select another candidate). Both class students can log in their system at any time to see: 1 ) whether the requests have responded; and 2) whether new requests arrive and then reply if necessary. 


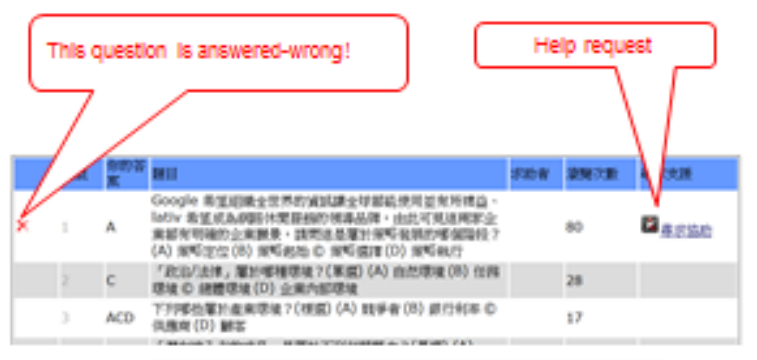

(a) The result of an assessment
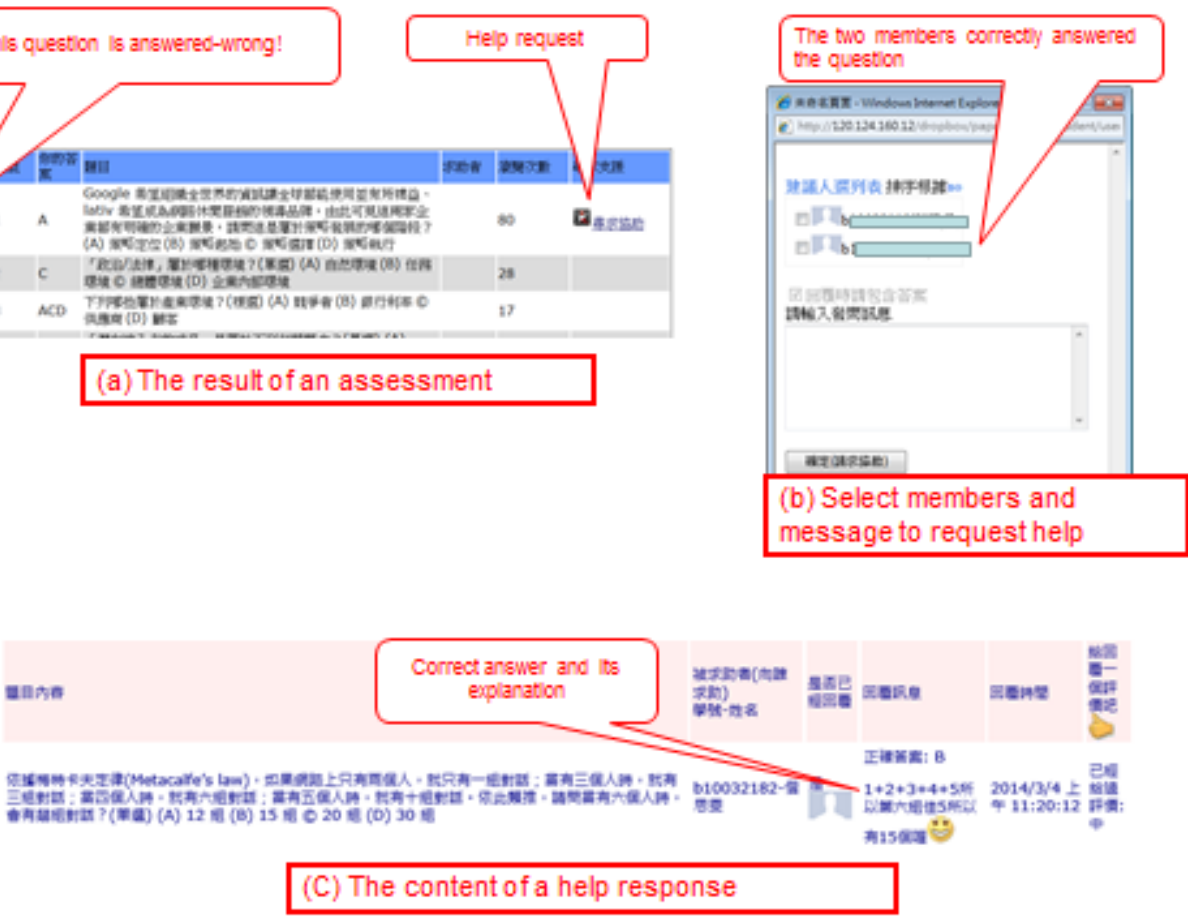

Figure 2. The functions for requesting help to members for both classes.

\section{The Provided GA Functions}

Restated, the major difference between the NA and GA classes was that the GA class provided the awareness of the contexts of learning interaction and knowledge of his/her group or other groups (i.e., the gray block "GA" in Figure 2) but the NA class did not.

As considered by Janssen et al. (2007, 2011), the context of learning interaction unveiled the number of help requests that a member had sent, the number of help requests that a member had received, the number of help requests that a member has responded to, and the response rate of each group member, as shown in Figure 3(a). The upper part of Figure 3(a) illustrates the statistics of member interaction context within one group. The lower part of Figure 3(a) illustrates the corresponding interaction diagram, reflecting who has requested to whom and how many times, and how many requests have been responded to. For example, the node b10032136 (student account) has an arrow labeled with 12/12 (as marked by a red rectangle) to the node b10032156, meaning b10032136 has requested help to b10032156 12 times and b10032156 also has responded 12 times. On the other hand, as considered by Sangin et al. (2011), the knowledge context unveiled a knowledge level (i.e., score) of every conducted assessments for each group member, as shown in Figure 3(b). As a reminder to use these provided GA functions, Figure 3(a) and (b) automatically displayed whenever a GA-class student logged in. 


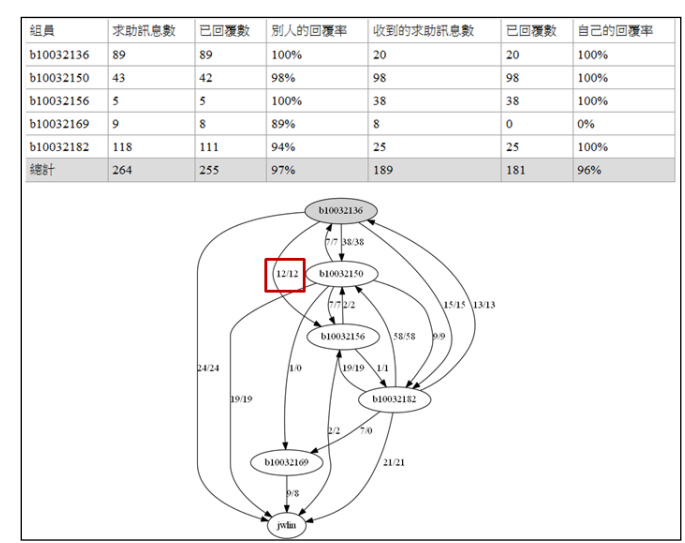

(c) The interaction context among group members

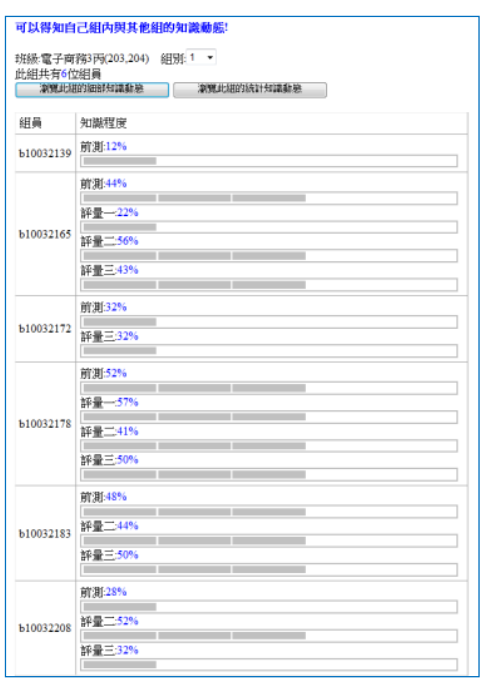

(d) The knowledge context of group members

Figure 3. The snapshots of GA (i.e., awareness of the contexts of member interaction and knowledge).

\section{Data Collection and Analysis}

Both systems recorded user activities as logged data, including login time, activities (i.e., taking an assessment, requesting help, or responding to help requests) and message properties (requestor, replier, time, content of request, and reply).

To understand the task (i.e., assessment) participation, we computed the number of taking assessments for every subject. To understand the patterns of peer interaction, this study investigated the behaviors of asking for help and willing to help of the subjects. We computed the "requesting rate" (i.e., asking for help) for every subject, which is defined as the accumulated number of help requests that a student has requested divided by the accumulated number of incorrectly-answered questions a student has conducted since first assessment began. Also, we computed the "responding rate" (i.e. willingness to help) for every subject, which is defined as the accumulated number of help requests that a student has responded to divided by the accumulated number of help requests that a student has received since first assessment began. Notably, the response rate calculation was only for the students who received ask-for-help messages. Thus, the number of students involved was distinct and was less than the total number of students for a given class, since only rarely did all the students in a class receive help.

This study used two-way analysis of variance (ANOVA) to examine how both variables, different systems (or different classes) (i.e., GA and NA) and different self-regulation levels (i.e., high and low), influence assessment participation (i.e., times), requesting rate, and responding rate. The different 
system types and different self-regulation levels were used as the independent variables, and the number of taking assessments, requesting rate, and responding rate were individually used as dependent variables. Whether both the variables interact with each other for these dependent variables were also verified.

\section{Result}

\section{Influence of Different Systems (or Classes) and Different Self-Regulation Levels on Online Assessment Participation}

Table 1 shows the descriptive statistics of the number of assessments students with high-level and low-level self-regulations has taken in both NA class and the GA class. Before analysis of two-way ANOVA, the homogeneity of variance assumption was tested and the $F$ values were $2.01(p>.05)$, indicating that the homogeneity assumption was not violated. Table 2 summarizes the two-way ANOVA results. Both variables, "different systems" and "different self-regulation levels," individually reached significances on the number of taking assessments $(F=12.67, \mathrm{p}<.05 ; F=4.13, p<.05)$. Most importantly, significant interaction occurred between these two variables on the number of taking assessments $(F=4.33, p<.05)$. Therefore, simple main effect of different systems and simple main effect of different self-regulation levels on the number of taking assessments had to be sequentially conducted using one-way ANOVA as follows.

This paragraph discusses the sample main effect of different systems (or classes). Before analysis of one-way ANOVA, the homogeneity of variance assumptions was tested and the $F$ values for NA and GA classes were $0.48(p>.05)$ and $1.23(p>.05)$ respectively, indicating that both homogeneities assumptions were not violated. The results showed that within the NA class, students with high-level self-regulation (mean $=1.56$ ) and with low-level self-regulation (mean $=1.58$ ) did not differ significantly $(F=0.00, p>.05)$. However, within the GA class, students with high-level self-regulation (mean $=4.00$ ) significantly had a higher number of taking assessments than students with low-level self-regulation $($ mean $=2.22)(\mathrm{F}=7.66, \mathrm{p}<.05)$.

This paragraph discusses the sample main effect of different self-regulation levels. Before analysis of one-way ANOVA, the homogeneity of variance assumptions was tested and the $F$ values for high-level and low-level self-regulation groups were $0.11(p>.05)$ and $1.54(p>.05)$ respectively, indicating that both homogeneities assumptions were valid. The results showed that students with high-level self-regulation in the GA class (mean $=4.00$ ) significantly were more willing to take assessments than students with high-level self-regulation in the NA class (mean $=1.56)(F=19.71, p<.05)$. However, the number of taking assessments between students with low-level regulation in the NA 
class $($ mean $=1.58)$ and those in the GA class $($ mean $=2.22)$ did not differ significantly $(F=0.91, p$ $>$.05).

Table 1

Descriptive Statistics of the Number of Taking Assessments $(n=99)$

\begin{tabular}{llcc}
\hline System (or Class) & Self-regulation level & Mean & $S D$ \\
\hline NA $(n=53)$ & High $(n=27)$ & 1.56 & 2.00 \\
& Low $(n=26)$ & 1.58 & 2.23 \\
GA $(n=46)$ & High $(n=23)$ & 4.00 & 1.85 \\
& Low $(n=23)$ & 2.22 & 2.46 \\
\hline
\end{tabular}

${ }^{*} p<.05 ;$

$S D$ : standard deviations; $n$, the number of students

Table 2

Two-Way ANOVA of the Number of Taking Assessments $(n=99)$

\begin{tabular}{|c|c|c|c|c|c|c|}
\hline Source & $S S$ & $d f$ & $M S$ & $F$-value & PostHoc ${ }^{a}$ & \\
\hline Different classes & 56.94 & 1 & 56.94 & $12.67^{*}$ & GA class $>$ NA class & \\
\hline Different self-regulation levels & 18.16 & 1 & 18.16 & $4.13^{*}$ & $\begin{array}{l}\text { High-level self-regulation } \\
\text { Low-level self-regulation }\end{array}$ & $>$ \\
\hline $\begin{array}{l}\text { Different classes } \\
\text { self-regulation levels }\end{array} *$ Different & 19.07 & 1 & 19.07 & $4 \cdot 33^{*}$ & & \\
\hline
\end{tabular}

${ }^{*} p<.05$.

aAdjustment for multiple comparisons: LSD (equivalent to no adjustments).

ANOVA, analysis of variance; $d f$, degrees of freedom; $L S D$, least significant difference; $M S$, mean square; $n$, the number of students; $S S$, sum of squares. 


\section{Influence of Different Systems and Different Self-Regulation Levels on Requesting Rate}

Table 3 shows the descriptive statistics of requesting rate for students with high-level and low-level self-regulations in both NA class and the GA class. Before analysis of two-way ANOVA, the homogeneity of variance assumption was tested and the $F$ values were $1.23(p>.05)$ indicating that the homogeneity assumption was not violated. Table 4 summarizes the two-way ANOVA results. Both variables, "different systems" and "different self-regulation levels," individually reached significances on requesting rate $(F=5.88, p<.05 ; F=4.58, p<.05)$. These two significant results respectively confirm with Newman (2002) which stated that contextual motivational resources (i.e., awareness of collaborative activities or GA) are conducive for exerting the learning behavior of help seeking and Ablard and Lipschultz (1998) which stated that students with a high-level of self-regulation are better at (or feel more comfortable in) social interaction situations and asking for assistance at appropriate times when encountering academic difficulties, as compared with students with a low-level of self-regulation.

Most importantly, significant interaction occurred between these two variables on the requesting rate $(F=4.21, p<.05)$. Therefore, simple main effect of different systems and simple main effect of the self-regulation levels on requesting rate had to be sequentially conducted using one-way ANOVA as follows.

Firstly, the sample main effects of different systems (classes) are discussed as follows. Before analysis of one-way ANOVA, the homogeneity of variance assumptions was tested and the $F$ values for NA and GA classes were $0.16(p>.05)$ and $2.12(p>.05)$ respectively, indicating that both homogeneities assumptions were not violated. The results showed that within the NA class, students with a high-level of self-regulation (mean $=0.59)$ and with a low-level of self-regulation $($ mean $=0.57)$ did not differ significantly $(F=0.00, p>.05)$. However, within the GA class, students with a high-level of self-regulation (mean $=1.33$ ) had significantly higher numbers of students taking assessments than those with a low-level of self-regulation $($ mean $=0.63)(F=6.61, \mathrm{p}<.05)$.

Secondly, the sample main effects of self-regulation levels are discussed as follows. Before analysis of one-way ANOVA, the $F$ values for the high-level and low-level self-regulation groups were 1.75 ( $p$ $>.05)$ and $0.47(p>.05)$ respectively, indicating that both homogeneity assumptions were not violated. The results showed that students with high-level self-regulation in the GA class (mean $=1.33$ ) had a significantly higher requesting rate than those in the NA class (mean $=0.59)(F=7.94, p<.05)$. However, requesting rates between students with a low-level of regulation in the NA class (mean = 0.57) and those in the GA class (mean $=0.63)$ did not differ significantly $(F=0.09, p>.05)$. 
Table 3

Descriptive Statistics of Requesting Rate ( $n=99)$

\begin{tabular}{lllc}
\hline System (or Class) & Self-regulation level & Mean & $S D$ \\
\hline NA $(n=53)$ & High $(n=27)$ & 0.59 & 0.73 \\
& Low $(n=26)$ & 0.57 & 0.72 \\
GA $(n=46)$ & High $(n=23)$ & 1.33 & 1.11 \\
& Low $(n=23)$ & 0.63 & 0.66 \\
\hline
\end{tabular}

${ }^{*} p<.05$

$S D$ : standard deviations; $n$, the number of students

Table 4

Two-Way ANOVA of Requesting Rate (n=99)

\begin{tabular}{|c|c|c|c|c|c|}
\hline Source & $S S$ & $d f$ & $M S$ & $F$-value & PostHoc \\
\hline Different classes & 3.97 & 1 & 3.97 & $5.88^{*}$ & GA class $>$ NA class \\
\hline Different self-regulation levels & 3.09 & 1 & 3.09 & $4 \cdot 58^{*}$ & $\begin{array}{l}\text { High-level self-regulation > Low-level } \\
\text { self-regulation }\end{array}$ \\
\hline $\begin{array}{l}\text { Different classes } \\
\text { self-regulation levels }\end{array}$ & 2.85 & 1 & 2.85 & $4.21^{*}$ & \\
\hline
\end{tabular}

${ }^{*} p<.05$

aAjustment for multiple comparisons: $L S D$ (equivalent to no adjustments).

ANOVA, analysis of variance; $d f$, degrees of freedom; $L S D$, least significant difference; $M S$, mean square; $n$, the number of students; $S S$, sum of squares. 


\section{Influence of Different Systems and Different Self-Regulation Levels on Responding Rate}

Table 5 shows the descriptive statistics of responding rate for students with high-level and low-level self-regulations in both NA class and the GA class. Before analysis of two-way ANOVA, the homogeneity of variance assumption was tested and the $F$ values were $0.62(p>.05)$, indicating that the homogeneity assumption was not violated. Table 6 summarizes the two-way ANOVA results. Only the variable "different classes" reached significance on responding rate $(F=9.14, p<.05)$. Students in the GA class (mean $=0.67$ ) had significantly higher responding rate than those in the NA class (mean $=0.37)(F=9.14, p<.05)$. These two variables had no significant interaction on responding rate.

Table 5

Descriptive Statistics of Responding Rate ( $n=79)$

\begin{tabular}{lllc}
\hline System (or Class) & Self-regulation level & Mean & $S D$ \\
\hline NA (n=40) & High $(n=21)$ & 0.40 & 0.44 \\
& Low $(n=19)$ & 0.34 & 0.46 \\
GA (n=39) & High $(n=21)$ & 0.68 & 0.42 \\
& Low $(n=18)$ & 0.66 & 0.42 \\
\hline
\end{tabular}

${ }^{*} \mathrm{p}<.05$

$S D$ : standard deviations; $n$, the number of students

Table 6

Two-Way ANOVA of Responding Rate ( $n=79)$

\begin{tabular}{lllllll}
\hline Source & $S S$ & $d f$ & $M S$ & F-value & PostHoc $^{a}$ \\
\hline Different classes & 1.77 & 1 & 1.77 & $9.14^{*}$ & GA class > NA class \\
Different self-regulation levels & 0.03 & 1 & 0.03 & 0.16 & \\
Different classes * Different self-regulation levels & 0.00 & 1 & 0.00 & 0.03 & \\
\hline
\end{tabular}

${ }^{*} p<.05$. 
aAdjustment for multiple comparisons: LSD (equivalent to no adjustments).

ANOVA, analysis of variance; df, degrees of freedom; $L S D$, least significant difference; $M S$, mean square; $n$, the number of students; $S S$, sum of squares.

\section{Discussion}

The first two parts of the experiment results (Table 2 and 4) showed that both variables, "different systems" and "different self-regulation levels," have significant interaction on assessment participation and requesting rate. Most importantly, GA appeared to particularly stimulate students with high-level self-regulation to engage more learning tasks (assessments) and ask for help more, compared with students with low-level self- regulation. These findings correspond to Savicki, Kelley, and Ammon (2002) which reported that GA dominates some group members.

From the prospective of social cognitive theory, self-regulation is context-specific and deeply influenced by contextual factors (Dembo \& Eaton, 2000; Yowell \& Smylie, 1999). Olasehinde and Olatoye (2014) also found that a significant positive relationship that existed between peer influence and self-regulation; that is, peer influence has greater influence on students with high-level self-regulation than students with students with low-level self-regulation. With understanding peer learning context through GA, students with high-level self-regulation, who are intrinsically better on adapting motivation strategy and learning behavior (e.g., asking for assistance) (Newman, 2002; Pintrich, 2004), become more motivated on adapting learning strategies, compared with students with low-level self-regulation. In our study, the GA tool, which can be deemed as an external stimulus, particularly influenced the learning behaviors of students with high-level self-regulation, in terms of higher assessment (task) participation and higher requesting rate (i.e., more asking for help). On the contract, students with low-level self-regulation intrinsically fail to adapt learning strategy and are less likely to activate constructive learning behaviors (Finkel \& Campbell, 2001). Additionally, peer influence has less influence on these students. Thus, GA has limited influences students with low-level self-regulation on assessment participation and higher requesting rate.

The third experiment results (Table 6) showed that both variables, "different systems" and "different self-regulation levels," have no significant interaction on responding rate (i.e., willing to help). The GA class had significantly higher responding rate than the NA class. Students with high-level and low-level self-regulations have no significant difference on responding rate.

The GA class had significantly higher responding rate than the NA class possibly because GA makes group norms visible. Perceiving and knowing that others have responded is likely to activate some degree of normative pressure (Bodemer, 2011) and this in turn will regulate the flow of collaboration (Janssen et al., 2011). Additionally, the motivation not to be rejected or disapproved by others can encourage individuals to be more responsible for peers' requests because individuals are protective of 
being perceived negatively by others (Janssen et al., 2007; Kimmerle \& Cress, 2008). For example, when the group awareness tool unveils that a member responded insufficiently, it can be a warning and negative signal illustrating "he/she is not responding," which is also available to other group members (Kwon et al., 2013).

Although Farley and Kim-Spoon (2014) stated that good self-regulators are better on using social interaction and students with less self-regulatory skills are less willing to help others, the experiment results showed that the responding rates between students with high-level and low-level self-regulations in both NA and GA classes have no significant difference. However, the mean of responding rate of students with high-level regulation is higher than that of students with low-level self-regulation in both NA and GA classes. The results of insignificant difference might result from that our sample was not large enough.

\section{Conclusion}

Despite the ability of group awareness and self-regulation to separately influence student learning, exactly how these two variables impact learning behavior has seldom been addressed. This paper focused on investigating how both variables, different systems (or different classes) (i.e., GA and NA) and different self-regulation levels (i.e., high and low), influence learning task (i.e., assessment) participation and peer interaction (i.e., asking for help and willing to help). Whether both variables interact with each other for assessment participation and peer interaction were also verified.

The important findings are as follows. Both variables have significant interaction on assessment participation and requesting rate. GA can particularly stimulate students with high-level self-regulation to have significantly higher learning task participation and asking for help more, compared with students with low-level self-regulation. Second, both variables have no significant interaction on responding rate. The GA class can enhance a student's willing to help regardless of his/her self-regulation level.

This paper focused on quantitative analysis. Janssen et al (2007) remained that investigations of message quality and quantity in a group awareness environment should go hand in hand. Thus, we will investigate how these two variables, different systems (GA and NA) and different self-regulation levels (high and low) influence on interaction (or message) quality in the future. For example, whether GA can particularly enhance the quality of response of students with high-level self-regulation when responding to help requests, compared with students with low-level self-regulation. However, only providing the knowledge level (score) might not be effective for eliciting quality response. Some extra mechanism, for example peer appraisement (i.e., a requestor can appraise the response of a helper as highly, medium, or lowly valuable content) (Wang, 2011), can be added into GA for peer reference. 


\section{References}

Ablard, K. E., \& Lipschultz, R. E. (1998). Self-regulated learning in high-achieving students: Relations to advanced reasoning, achievement goals, and gender. Journal of Educational Psychology, 9o(1), 94-101.

Aleven, V., \& Koedinger, K. R. (2001). Investigations into help seeking and learning with a cognitive tutor. In R. Luckin (Ed.), Papers of the AIED-2001 workshop on help provision and help seeking in interactive learning environments (pp. 47-58). Retrieved from http://www.hcrc.ed.ac.uk/aied2001/workshops.html.

Barnard, L., Lan, W., To, Y., Paton, V., \& Lai, S. (2009). Measuring self-regulated in online and blended learning environments. Internet and Higher Education, 12(1), 1-6.

Bodemer, D. (2011). Tacit guidance for collaborative multimedia learning. Computers in Human Behavior, 27, 1079-1086.

Bodemer, D., \& Dehler, J. (2011). Group awareness in CSCL environments. Computers in Human Behavior, 27, 1043-1045.

Buder, J. (2011). Group awareness tools for learning: Current and future directions. International Computers in Human Behavior, 27, 1114-1117.

Dehler, J., Bodemer, D., Buder, J., \& Hesse, F. W. (2011). Guiding knowledge communication in CSCL via group knowledge awareness. Computers in Human Behavior, 27, 1068-1078.

Dembo, M. H., \& Eaton, M. J. (2000). Self-regulation of academic learning in middle-level schools. The Elementary School Journal, 10o(5), 473-490.

Engelmann, T., Tergan, S., \& Hesse, F. W. (2010). Evoking knowledge and information awareness for enhancing computer-supported collaborative problem solving. Journal of Experimental Education, 78(2), 268-290.

Farley, J. P., \& Kim-Spoon, J. (2014). The development of adolescent self-regulation: Reviewing the role of parent, peer, friend, and romantic relationships. Journal of Adolescence, 37(4), 433-440.

Finkel, E. J., \& Campbell, W. K. (2001). Self-control and accommodation in close relationships: An interdependence analysis. Journal of Personality and Social Psychology, 81, 263-277. . 
Fjermestad, J. (2004). An analysis of communication mode in group support systems research. Decision Support Systems, 37(2), 239-263.

Holocher-Ertl, T., Fabian, C. M., Siadaty, M., Jovanović, J., Pata, K., \& Gasevic, D. (2011). Self-regulated learners and collaboration: How innovative tools can address the motivation to learn at the workplace? Lecture Notes in Computer Science, 6964, 506-511.

Janssen, J., Erkens, G., Kanselaar, G., \& Jaspers, J. (2007). Visualization of participation: Does it contribute to successful computer-supported collaborative learning? Computers \& Education, 49, 1037-1065.

Janssen, J., Erkens, G., \& Kirschner, P. A. (2011). Group awareness tools: It's what you do with it that matters. Computers in Human Behavior, 27, 1046-1058.

Kimmerle, J., \& Cress, U. (2008). Group awareness and self-presentation in computer-supported information exchange. International Journal of Computer-Supported Collaborative Learning, 3(1), 85-97.

Kreijns, K., Kirschner, P. A., \& Jochems, W. (2003). Identifying the pitfalls for social interaction in computer-supported collaborative learning environments: A review of the research. Computers in Human Behavior, 19(3), 335-353.

Kwon, J., Hong, R. Y., \& Laffey, J. M. (2013). The educational impact of metacognitive group coordination in computer-supported collaborative learning. Computers in Human Behavior, 29, 1271-1281.

Lin, J. W., \& Lai, Y. C. (2013). Online formative assessments with social network awareness. Computers \& Education, 66, 40-53.

Lin, J. W., Huang, H. H., \& Chuang, Y. S (2015). The impacts of network centrality and self-regulation on an e-learning environment with the support of social network awareness. British Journal of Educational Technology, 46(1), 32-44.

McManus, T. F. (2000). Individualizing instruction in a web-based hypermedia learning environment: nonlinearity, advance organizers, and self-regulated learners. Journal of Interactive Learning Research, 11, 219-251.

Newman, R. S. (2002). How self-regulated learners cope with academic difficulty: The role of adaptive help seeking. Theory into Practice, 41(2), 132-138. 
Olasehinde, K. J., \& Olatoye, R. A. (2014). Self-regulation and peer influence as determinants of senior secondary school students' achievement in science. Mediterranean Journal of Social Sciences, 5(7), 374 .

Pintrich, P. R. (2004). A conceptual framework for assessing motivation and self-regulated learning in college students. Educational Psychology Review, 16(4), 358-407.

Sangin, M., Molinari, G., Nüssli, M. A., \& Dillenbourg P. (2011). Facilitating peer knowledge modeling: Effects of a knowledge awareness tool on collaborative learning outcomes and processes. Computers in Human Behavior, 27(3), 1059-1067.

Savicki, V., Kelley, M., \& Ammon, B. (2002). Effects of training on computer-mediated communication in single or mixed gender small task groups. Computers in Human Behavior, 18(3), 257-270.

Schunk, D. H. (1994). Self-regulated of self-efficacy and attributions in academic settings. In D. H. Schunk and B. J. Zimmermann (Eds.), Self-regulated of learning performance. Issues and educational applications (pp. 75-99). Lawrence Erlbaum Associates, Hillsday, New Jersey,

Shea, P., \& Bidjerano, T. (2012). Learning presence as a moderator in the community of inquiry model. Computers \& Education, 59, 326-326.

Shi, Y., Frederiksen, C. H., \& Muis, K. R. (2013). A cross-cultural study of self-regulated learning in a computer-supported collaborative learning environment. Learning and Instruction, 23, 52-59.

Wang, T. H. (2011). Developing web-based assessment strategies for facilitating junior high school students to perform self-regulated learning in an e-Learning environment. Computers \& Education, 57(2), 1801-1812.

Yowell, C. M., \& Smylie, M. A. (1999). Self-regulation in democratic communities. Elementary School Journal, 99, 469-490.

Zimmerman, B. J. (1989). A social cognitive view of self-regulated academic learning. Journal of Educational Psychology, 81(3), 329-339.

\section{Athabasca \\ University}

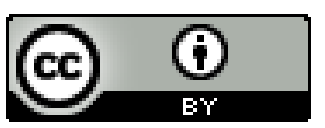

